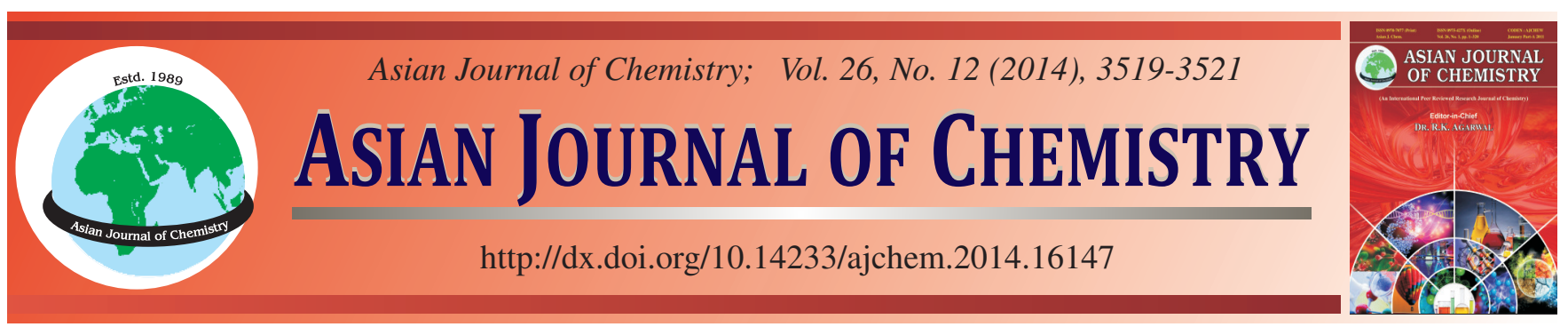

\title{
Novel Functional Mesoporous Silicas for Separating and Pre-Concentrating Trace Chromium Ion in Fireworks and Firecracker
}

\author{
F.M. JIANG ${ }^{1}$, F.L. REN ${ }^{1, *}$, Q.L. LIAO ${ }^{2}$, F. FANG ${ }^{1,3}$ and T.F. YI ${ }^{4}$
}

\begin{abstract}
${ }^{1}$ Laboratory of Resources Chemistry of Nonferrous Metals, Central South University, Changsha 410083, P.R. China ${ }^{2}$ Changsha Economic and Technical Development Zone Water Purification Engineering Co. Ltd, Changsha 410199, P.R. China ${ }^{3}$ College Of Chemistry and Biological Engineering, Changsha University of Science and Technology, Changsha 410114, P.R. China ${ }^{4}$ Exit-Entry Inspection and Quarantine Bureau, Changsha 410004, P.R. China
\end{abstract}

*Corresponding author: Fax: +98 21 22222512; Tel: +86 731 83670779; E-mail: renfenglian2011@163.com

Received: 5 August 2013; $\quad$ Accepted: 13 November 2013; $\quad$ Published online: 5 June 2014;

\begin{abstract}
A sensitive and selective method has been developed for chromium ion in fireworks and firecracker, using functional mesoporous silica materials as the absorbents combined with the inductively coupled plasma optical emission spectrometer (ICP-OES) method. The mesoporous silica materials were functionalized with 2-mercaptobenzothiazole utilizing potassium iodide as catalyst and ecofriendly ethanol as solvent, which were applied in fabricating a minicolumn to preconcentrate the chromium solution, concentration of which was then determined by ICP-OES. The pre-concentration conditions including $\mathrm{pH}$, temperature, adsorption time, eluent, elution time and effects of coexisting ions were discussed. The detection limit for $\mathrm{Cr}$ was $0.45 \mu \mathrm{g} \mathrm{L}^{-1}$ and the relative standard deviation for six replicate runs was $2.9 \%$. The proposed method has been applied to the determination of chromium ion in fireworks and firecracker samples with satisfactory results.
\end{abstract}

Keywords: Mesoporous silica, 2-Mercaptobenzothiazole, Chromium, Fireworks and firecracker.

\section{INTRODUCTION}

Fireworks and firecracker is one of the most well-known consumer goods around the world. The heavy metal contamination coming from fireworks and firecracker ${ }^{1,2}$ is of increasing concern because of its great threaten to human health ${ }^{3-5}$. Lead, mercury and chromium identified as highly toxic elements will be gradually accumulated in organism body and further threaten human health through food chains. These heavy metal ions are frequently determined by atomic emission spectrometry $(\mathrm{AES})^{6}$, atomic absorption spectrometry $(\mathrm{AAS})^{7,8}$, atomic fluorescence spectrophotometry (AFS) ${ }^{9}$, and stripping voltammetry ${ }^{10}$. However, the detection limit of these methods could hardly satisfy the requirement for environment analysis.

Thus, pre-concentration of these trace metal ions is very necessary. To this end, activated carbons ${ }^{11}$, chelating resin ${ }^{12}$, mesoporous sieves ${ }^{13}$, chitosans $^{14}$, sulfhydryl cotton ${ }^{15}$, etc. are traditionally used, among which mesoporous silica is excellent in pre-concentration ability for their large pore size, surface area and high stability. Unfortunately, raw, unmodified mesoporous silicas still suffer from the weak adsorption capacity. As a result, some attempts have been made to modify the mesoporous silica materials by a chemical means to improve their adsorption ability.

In this work, mesoporous silica was successfully functionalized by MBT-MCM-41-new via the one-pot copolycondensation in ethanol as reported in previous paper ${ }^{16}$, and then it was used to enrich chromium ion in fireworks and firecracker samples. The conditions including $\mathrm{pH}$, adsorption time, eluent and elution time were optimized. The materials turned out to be able to better pre-concentrate the trace amount of $\mathrm{Cr}$ ion, satisfying the requirement for ICP-OES analysis.

\section{EXPERIMENTAL}

FT-IR spectra was obtained from Nicolet 6700 (Nicolet Company) with the usual $\mathrm{KBr}$ pellet method. Scanning electron microscope (SEM) was performed on SIRION200 (FEI company America). The $\mathrm{pH}$ values were measured by a $\mathrm{pH}-$ meter (pHS$3 \mathrm{C}$, China). The ion concentrations remaining in the solutions were analyzed by an inductively coupled plasma optical emission spectrometer (ICP-OES, Varian 715-ES, America). The operation conditions and analytical wavelength are summarized in Table- 1 .

Standard solution and reagents: Tetraethyl orthosilicate (TEOS, AR, West Long Chemical Co., Ltd.), HCl (37 \%, AR, Hensel Chemical Reagent Co., Ltd.), ethanol (95\%, AR, Anhui Ante biochemical Co., Ltd.). Tetramethyl ammonium hydroxide (TMAOH, $25 \%$ ), cetyltrimethyl ammonium bromide (CTAB), 2-mercaptobenzothiazole (MBT), 3-chloropropyl-triethoxysilane (CPTS) and potassium iodide (KI) were of analytical reagent grade. Doubly distilled deionized water was used throughout. Standard metal ion solutions were prepared for $100 \mathrm{mg} \mathrm{L}^{-1}$. 


\begin{tabular}{lc}
\hline \multicolumn{2}{c}{ TABLE-1 } \\
ICP-OES OPERATING CONDITIONS AND \\
THE ANALYTICAL WAVELENGTH \\
\hline \multicolumn{2}{c}{ Parameters } \\
\hline \multicolumn{2}{c}{ RF power (W) } \\
Plasma gas (Ar) flow rate $\left(\mathrm{L} \mathrm{min}^{-1}\right)$ & 1200 \\
Auxiliary gas flow rate $\left(\mathrm{L} \mathrm{min}^{-1}\right)$ & 15 \\
Pumping rate (mL min & -1.5 \\
Observation height $(\mathrm{mm})$ & 1.5 \\
Analytical wavelength $(\mathrm{Cr})(\mathrm{nm})$ & 10 \\
\hline
\end{tabular}

Preparation of adsorbents: MCM-41 was prepared as the method reported by Yang $e t$ al. ${ }^{17} \mathrm{CTAB}(3.9 \mathrm{~g})$ was dissolved in $89 \mathrm{~mL} \mathrm{H}_{2} \mathrm{O}$ and $1 \mathrm{~mL}$ TMAOH $(25 \%)$ under stirring at $40{ }^{\circ} \mathrm{C}$. Then, $10 \mathrm{~mL}$ TEOS was slowly added under stirring and the gel formation began to be visible after $10 \mathrm{~min}$. The homogeneous gel was transferred into a Teflon-lined autoclave and treated under autogenous pressure at $90{ }^{\circ} \mathrm{C}$ for $24 \mathrm{~h}$. The obtained product was extracted for $24 \mathrm{~h}$ by a Soxhlet extractor with $90 \mathrm{~mL} \mathrm{HCl}\left(1.2 \mathrm{~mol} \mathrm{~L}^{-1}\right)$ and $90 \mathrm{~mL}$ ethanol. The finally product was dried at $100{ }^{\circ} \mathrm{C}$ approximately for $5 \mathrm{~h}$.

Potassium iodide $(4.2 \mathrm{~g})$ and $4.0 \mathrm{~mL}$ CPTS were added into $80 \mathrm{~mL}$ ethanol $(95 \%)$ at $40{ }^{\circ} \mathrm{C}$ under stirring for $2 \mathrm{~h}$. Then $4.2 \mathrm{~g} \mathrm{MBT}$ was added into the mixture and kept stirring for $3 \mathrm{~h}$ at the same temperature. After reaction, $2 \mathrm{~g} \mathrm{MCM}-41$ was separately put into the mixed solution and then refluxed at $90{ }^{\circ} \mathrm{C}$ for $12 \mathrm{~h}$. Then the product was washed by ethanol for several times to remove iodine ions. Finally the filtered product was dried at $100{ }^{\circ} \mathrm{C}$ for $5 \mathrm{~h}$. It was marked as MBT-MCM-41-new.

General procedure: Microcolumn $(80 \times 5 \mathrm{~mm}$ i.d.) filled with MBT-MCM-41-new was pre-activated for $2 \mathrm{~h}$ with $\mathrm{HCl}$ $\left(0.1 \mathrm{~mol} \mathrm{~L}^{-1}\right)$ and $\mathrm{NaHCO}_{3}\left(0.5 \mathrm{~mol} \mathrm{~L}^{-1}\right)$, respectively. Standard Cr ion solutions or real samples $(500 \mathrm{~mL})$ were prepared with the proper $\mathrm{pH}$ (avoid precipitation). They were passed through the microcolumn with the flow rate of $2 \mathrm{~mL} \mathrm{~min}^{-1}$. The column filtrate was determined by ICP-AES to calculate the removal rate $\delta$ and adsorption capacity QM $\left(\mathrm{mmol} \mathrm{g}^{-1}\right)$. The retained column was eluted with different eluents and then determined by ICP-OES.

\section{RESULTS AND DISCUSSION}

Characterization of MBT-MCM-41-new: The synthesized MCM-41 was characterized by SEM, IR spectrum and melting point determination. Fig. 1 displayed that the mesoporous silica MBT-MCM-41-new has a uniform pore distribution with pore size of about $2 \mathrm{~nm}$. FT-IR (KBr) was shown in Fig. 2. The broad band in the range of $3716-2991 \mathrm{~cm}^{-1}$ is the vibration peak of $\mathrm{H}_{2} \mathrm{O}$. Peaks of 1631 and $949 \mathrm{~cm}^{-1}$ are the bending vibrations of $-\mathrm{OH}$. The bands around 1083, 798 and $465 \mathrm{~cm}^{-1}$ result from Si-O-Si vibrations. The vibration peak of $\mathrm{C}-\mathrm{S}$ is $1437 \mathrm{~cm}^{-1} ; 737 \mathrm{~cm}^{-1}$ corresponds to the peak of benzene; $2925 \mathrm{~cm}^{-1}$ is contributed to the methylene of MBT and 1430 $\mathrm{cm}^{-1}$ is the vibration peak of $\mathrm{C}=\mathrm{N}$. The characteristic bands demonstrate that MBT has been successfully anchored onto the silica surfaces.

Effect of $\mathrm{pH}$ on Cr adsorption of MBT-MCM-41-new: The $\mathrm{pH}$ values of chromium standard solutions $\left(50 \mu \mathrm{g} \mathrm{L}^{-1}\right)$ were adjusted to a range of $1-8$ by $\mathrm{KH}_{2} \mathrm{PO}_{4}$ and $\mathrm{Na}_{2} \mathrm{~B}_{4} \mathrm{O}_{7} \cdot 10 \mathrm{H}_{2} \mathrm{O}$. $0.5 \mathrm{~g}$ of MBT-MCM-41-new was respectively added into the

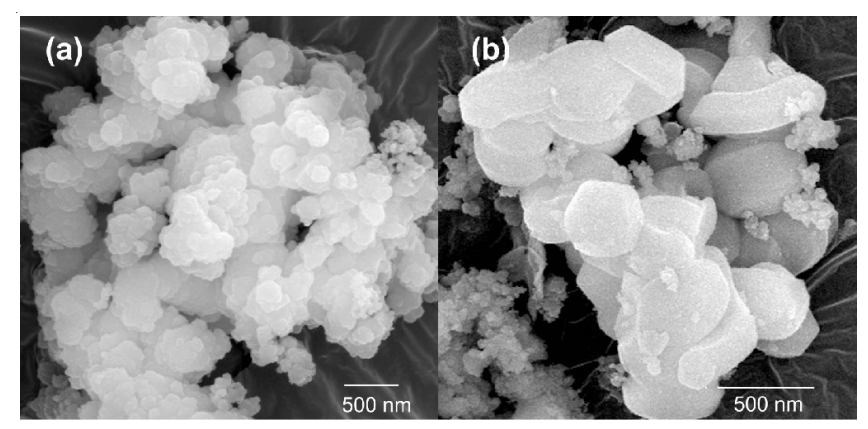

Fig. 1. SEM of MCM-41 (a) and MBT-MCM-41-new (b)

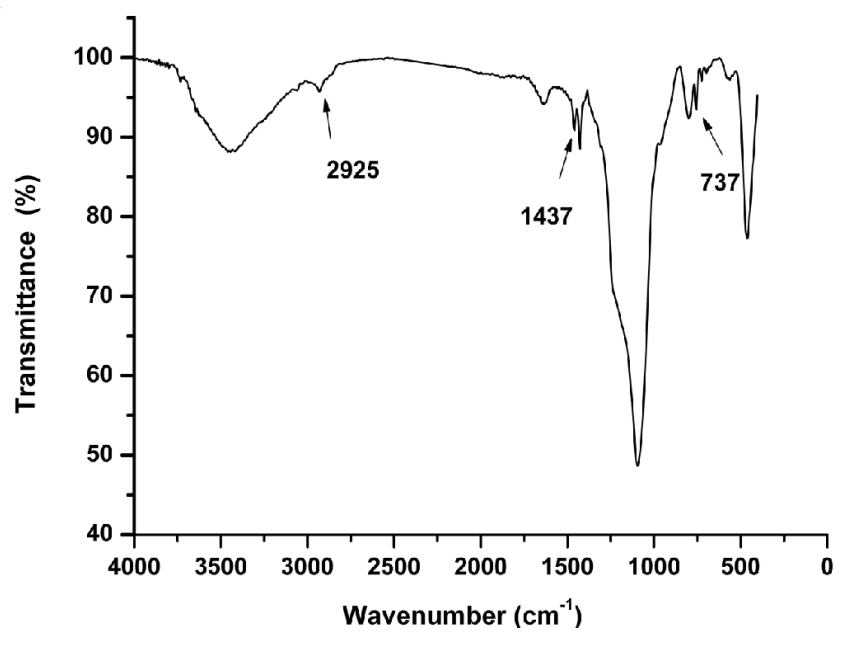

Fig. 2. FT-IR spectra of MBT-MCM-41-new

solution and handled as general procedure. The results of adsorption rate of $\mathrm{Cr}$ for MBT-MCM-41-new under different acidity are shown in Fig. 3, which indicate that the adsorption rate reached maximum value when $\mathrm{pH}$ was 6 . Therefore $\mathrm{pH} 6$ was chosen as the adsorption medium acidity in the experiments.

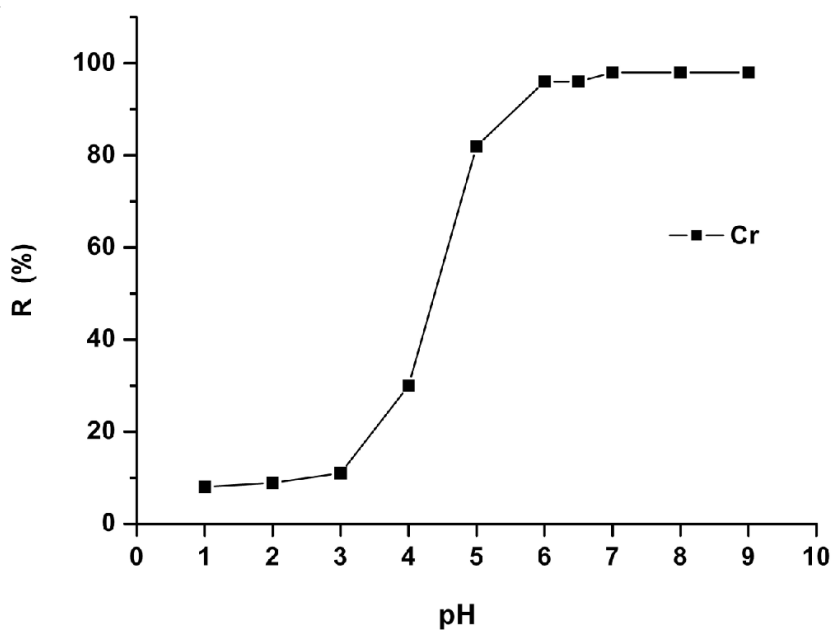

Fig. 3 Effect of pH on Cr adsorption of MBT-MCM-41-new

Effects of enrichment temperature and time: At $\mathrm{pH}$ 6, the influence of enrichment temperature on adsorption rate from $50 \mu \mathrm{g} \mathrm{L}{ }^{-1}$ of $\mathrm{Cr}$ standard solution was determined. The experimental results show that the temperature on chromium adsorption rate is very small, so room temperature was selected for enrichment. 
The affection of adsorption time on adsorption rate of chromium was carried out with other conditions fixed and the results were shown as Fig. 4. The $\mathrm{Cr}$ adsorption rate can reach above $98.5 \%$. The adsorption time in this experiment is $20 \mathrm{~min}$.

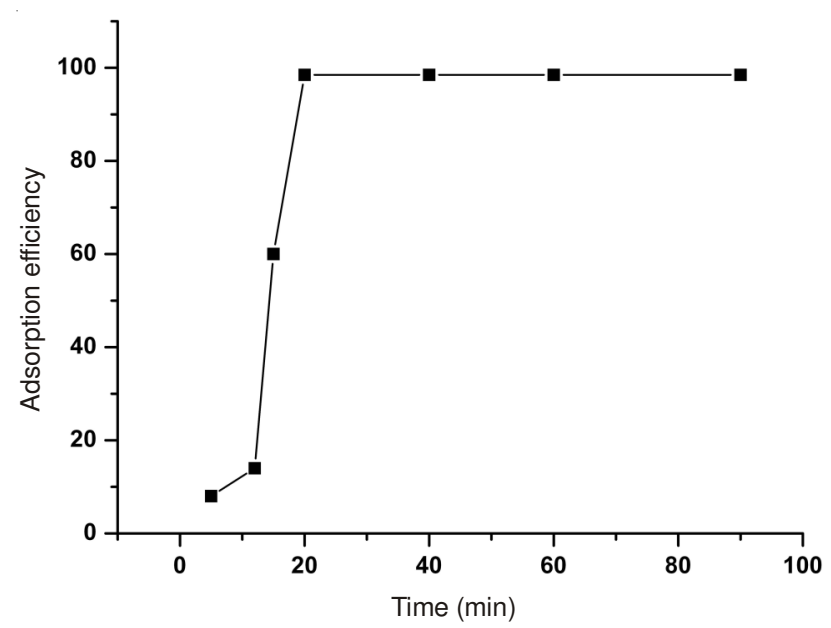

Fig. 4. Effect of enrichment time on Cr adsorption of MBT-MCM-41-new

Adsorption capacity: Under the optimized experimental conditions, $100 \mathrm{~mL}$ standard ion solutions $\left(10-100 \mu \mathrm{g} \mathrm{L} \mathrm{L}^{-1}\right)$ were passed through the column filled with sorbents $(0.5 \mathrm{~g})$ with a flow-rate of $2 \mathrm{~mL} \mathrm{~min}^{-1}$. The after-reacting liquid was determined by ICP-OES. The saturated capacity $\mathrm{Q}_{\max }$ of MBT-MCM41-new is $9.23 \mathrm{mg} \mathrm{g}^{-1}$.

Effects of eluent and elution time: Elution of $\mathrm{Cr}$ from the sorbents MBT-MCM-41-new was investigated by using different reagents as eluents, including $\mathrm{HC} 1$, dilute $\mathrm{HCl}+\mathrm{NaCl}$ saturated solution, EDTA, thiourea, $\mathrm{HNO}_{3}, \mathrm{HNO}_{3}-\mathrm{SnCl}_{2}$ hydroxylamine hydrochloride in different concentrations, respectively. Results show that elution efficiency of $2 \mathrm{~mol} \mathrm{~L}^{-1}$ $\mathrm{HCl}$ is best and $5 \mathrm{~min}$ of elution time is enough for $2 \mathrm{~mol} \mathrm{~L}^{-1}$ $\mathrm{HCl}$ to desorb all of the $\mathrm{Cr}$ ions.

Effects of coexisting ions: The effects of common coexisting ions on the determination of $\mathrm{Cr}$ were investigated. In these experiments, solutions of $0.05 \mathrm{mg} \mathrm{L}^{-1}$ of $\mathrm{Cr}$ containing the added interfering ions were treated according to the recommended procedure. The tolerance of the coexisting ions were $\mathrm{Mg}^{2+}$, $\mathrm{Ca}^{2+}, \mathrm{Al}^{3+} 5 \mathrm{~g} \mathrm{~L}^{-1}, \mathrm{~Pb}^{2+}, \mathrm{Ni}^{2+}, \mathrm{Mn}^{2+} 0.5 \mathrm{~g} \mathrm{~L}^{-1}, \mathrm{Zn}^{2+}, \mathrm{Cu}^{2+}, \mathrm{Ag}^{+}$, $\mathrm{Au}^{3+} 25 \mathrm{mg} \mathrm{L}^{-1}, \mathrm{Hg}^{2+} 5 \mathrm{mg} \mathrm{L}^{-1}$. It can be seen that the presence of major ions has no obvious influence on the determination under the selected conditions.

Detection limits and precision: According to the definition of IUPAC, the detection limit (3s) of this method for $\mathrm{Cr}$ with an enrichment factor of 50 is $0.45 \mu \mathrm{g} \mathrm{L}^{-1}$. The relative standard deviation (R.S.D) is $2.9 \%$.

Analysis of real samples: The proposed method has been applied to analyze total chromium in fireworks and firecracker samples. The standard addition method was used and the analytical results and the recovery were given in Table- 2 . The results indicated that the recoveries were reasonable for trace analysis in a range of 95.8-101.2\%.

\begin{tabular}{ccccc}
\multicolumn{5}{c}{ TABLE-2 } \\
DETERMINATION RESULTS OF REAL SAMPLES \\
\hline \multirow{2}{*}{ Samples } & $\begin{array}{c}\text { Added } \\
\left(\mu \mathrm{g} \mathrm{L}^{-1}\right)\end{array}$ & $\begin{array}{c}\text { Found } \\
\left(\mu \mathrm{g} \mathrm{L}^{-1}\right)\end{array}$ & $\begin{array}{c}\text { Recovery } \\
(\%)\end{array}$ & $\begin{array}{c}\text { RSD }(\%) \\
\mathrm{n}=6\end{array}$ \\
& 0 & 4.82 & -- & 2.9 \\
\multirow{2}{*}{ Rocket } & 5.00 & 9.61 & 95.8 & 1.8 \\
\hline \multirow{2}{*}{ Shell } & 0 & 6.30 & -- & 2.3 \\
& 5.00 & 11.23 & 98.6 & 2.5 \\
\hline \multirow{2}{*}{ Cake } & 0 & 5.73 & -- & 2.7 \\
& 5.00 & 10.79 & 101.2 & 2.3 \\
\hline
\end{tabular}

\section{Conclusion}

In this work, the absorption of Cr on MBT-MCM-41-new was investigated. Based on its high absorption selectivity for $\mathrm{Cr}$, a sensitive and selective method for the separation and determination of chromium in fireworks and firecracker using functional mesoporous silica MBT-MCM-41-new materials and inductively coupled plasma optical emission spectrometer (ICP-OES) was developed. The absorption capacity of MBTMCM-41-new reached $9.23 \mathrm{mg} \mathrm{g}^{-1}$. The developed method has been successfully applied to the determination of chromium in fireworks and firecracker.

\section{ACKNOWLEDGEMENTS}

This work was financially supported by project of Scientific Research Fund of China Hunan Provincial Science and Technology Department (No. 2012FJ4259) and project of National Natural Science Foundation of China (No. 51104024) and project of General Administration of Quality Supervision, Inspection and Quarantine of P.R. China (No. 2014IK074).

\section{REFERENCES}

1. L.Z. Zhou, S. Fu, S.Q. Gao and F.Q. Zhou, J. Instrum. Anal., 28, 173 (2009).

2. Y.P. Jiang, C.G. Huang, Y.H. Zheng, H. Zhao and M.S. Liu, Chem. Anal. Meterage, 19, 59 (2010).

3. J.O. Duruibe, M.O.C. Ogwuegbu and J.N. Egwurugwu, Int. J. Phys. Sci., 2, 112 (2007).

4. L. Jarup, Br. Med. Bull., 68, 167 (2003).

5. L. Cai, Z. Xu, M. Ren, Q. Guo, X. Hu, G. Hu, H. Wan and P. Peng, Ecotoxicol. Environ. Saf., 78, 2 (2012).

6. S. Baytak, F. Zereen and Z. Arslan, Talanta, 84, 319 (2011).

7. A. Martín-Esteban, Talanta, 48, 959 (1999).

8. J.L. Guzmán-Mar, L. Hinojosa-Reyes, A.M. Serra, A. HernándezRamírez and V. Cerdà, Anal. Chim. Acta, 708, 11 (2011).

9. D.L. Giokas, G.Z. Tsogas, A.G. Vlessidis and M.I. Karayannis, Anal. Chem., 76, 1302 (2004).

10. J.M. Trindade, L.C. Martiniano, V.R.A. Gonçalves, A.G. Souza, A.L.B. Marques, G.L. Baugis, T.C.O. Fonseca, C. Song, J. Zhang and E.P. Marques, Fuel, 91, 26 (2012).

11. C.P. Dwivedi, J.N. Sahu, C.R. Mohanty, B.R. Mohan and B.C. Meikap, J. Hazard. Mater., 156, 596 (2008).

12. B.N. Kumar, D.K. Venkata Ramana, Y. Harinath, K. Seshaiah and M.C. Wang, J. Agric. Food Chem., 59, 11352 (2011).

13. X. Chai, X. Chang, Z. Hu, Q. He, Z. Tu and Z. Li, Talanta, 82, 1791 (2010).

14. M. Hosoba, K. Oshita, R.K. Katarina, T. Takayanagi, M. Oshima and S. Motomizu, Anal. Chim. Acta, 639, 51 (2009).

15. M. Zeng, Yejin Fenxi, 27, 44 (2007).

16. F.M. Jiang, Q.M. Pu, F.L. Ren, H.Q. Huang, F.Y. Cao, Y. Li and B. Wang, Mater. Res. Innov., 17, 122 (2013).

17. H. Yang, R. Xu, X.M. Xue, F.T. Li and G.T. Li, J. Hazard. Mater., 152, 690 (2008) 